\title{
Viewpoint \\ Targeting the ubiquitin proteasome pathway for the treatment of septic shock in patients Jan Brun ${ }^{1,2,3}$ and Douglas A Gray ${ }^{1,2}$
}

\author{
1 Ottawa Health Research Institute, Ottawa, ON, Canada K1Y 4E9 \\ 2Department of Biochemistry, Microbiology, and Immunology, University of Ottawa, Ottawa, ON, Canada K1H 8M5 \\ ${ }^{3}$ Apoptosis Research Centre, Children's Hospital of Eastern Ontario, Ottawa, ON, Canada K1H 8L1
}

Corresponding author: Douglas A Gray, dgray@ohri.ca

Published: 14 August 2009

This article is online at http://ccforum.com/content/13/4/311

(c) 2009 BioMed Central Ltd

Critical Care 2009, 13:311 (doi:10.1186/cc7946)

Figure 1

Abstract

Endotoxic shock is a serious systemic inflammatory response to an external biological stressor. The responsiveness of NF- $\mathrm{KB}$ is built upon rapid protein modification and degradation involving the ubiquitin proteasome pathway. Using transgenic mice, we have obtained in vivo evidence that interference with this pathway can alleviate the symptoms of toxic shock. We posit that administration of proteasome inhibitors may enhance the survival of patients with septic shock.

\section{Multiple myeloma, endotoxic shock and proteasome inhibitors}

Multiple myeloma (MM) provides an example of the functional importance of ubiquitin in the NF- $\kappa B$ pathway [1,2]. A drug that shows great promise against MM is Velcade (bortezomib, formerly PS-341), a specific reversible inhibitor of proteasome function and, hence, ubiquitin-mediated proteolysis (Figure 1). Velcade is thought to block the activation of NF- $\mathrm{KB}$ and thereby deprive $\mathrm{MM}$ cells of the signals that are otherwise constitutive. In cell culture and animal studies Velcade has shown considerable activity against $\mathrm{MM}$ cells and is now in phase II and III human clinical trials [3,4].

Despite available therapies, including corticosteroids, volume replacement, antibiotics, and vasopressor support, endotoxic shock remains a common cause of death in ICUs [5]. It is characterized by hypotension, vascular damage, and inadequate tissue perfusion, often leading to the failure of many organ systems, including liver, kidney, heart and lungs, after systemic bacterial infection $[1,5,6]$. The pathogenesis of septic shock seems to be primarily governed by lipopolysaccharide (LPS). Significantly, NF- $\mathrm{KB}$ activation is a central component in septic shock, stimulating the expression of several proinflammatory proteins such as TNF- $\alpha$, IL-1 $1 \beta, \mathrm{IL}-6$, and inducible nitric

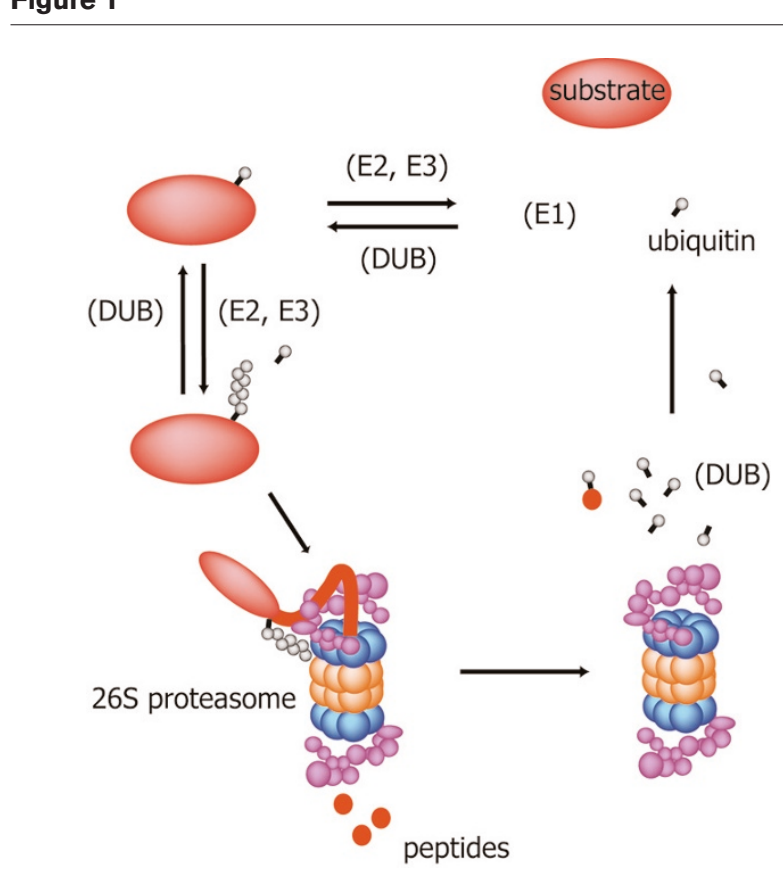

Ubiquitin proteasome pathway. An E1, E2 and E3 complex promotes the ubiquitination of protein substrates via K48 linkage, which predominantly targets substrates for proteasomal degradation. This process is reversible though the action of deubiquitinating enzymes (DUBs) that can cleave ubiquitin from the modified proteins.

oxide synthase $[1,7]$. Moreover, NF-kB is stimulated by these endogenous mediators in a paracrine and autocrine fashion. It is conceivable, therefore, that inhibition of NF- $\mathrm{kB}$ activation by a rapid acting proteasome inhibitor may be of potential therapeutic benefit in the treatment of septic shock [8].

$\mathrm{CLP}=$ cecal ligation and puncture; $\mathrm{IKK}=\mathrm{I} \mathrm{\kappa B}$ kinase; $\mathrm{IL}=$ interleukin; $\mathrm{LPS}=$ lipolysaccharide; $\mathrm{MM}=$ multiple myeloma; $\mathrm{NF}=$ nuclear factor; $\mathrm{TNF}=$ tumor necrosis factor; TRAF = TNF-receptor-associated factor. 


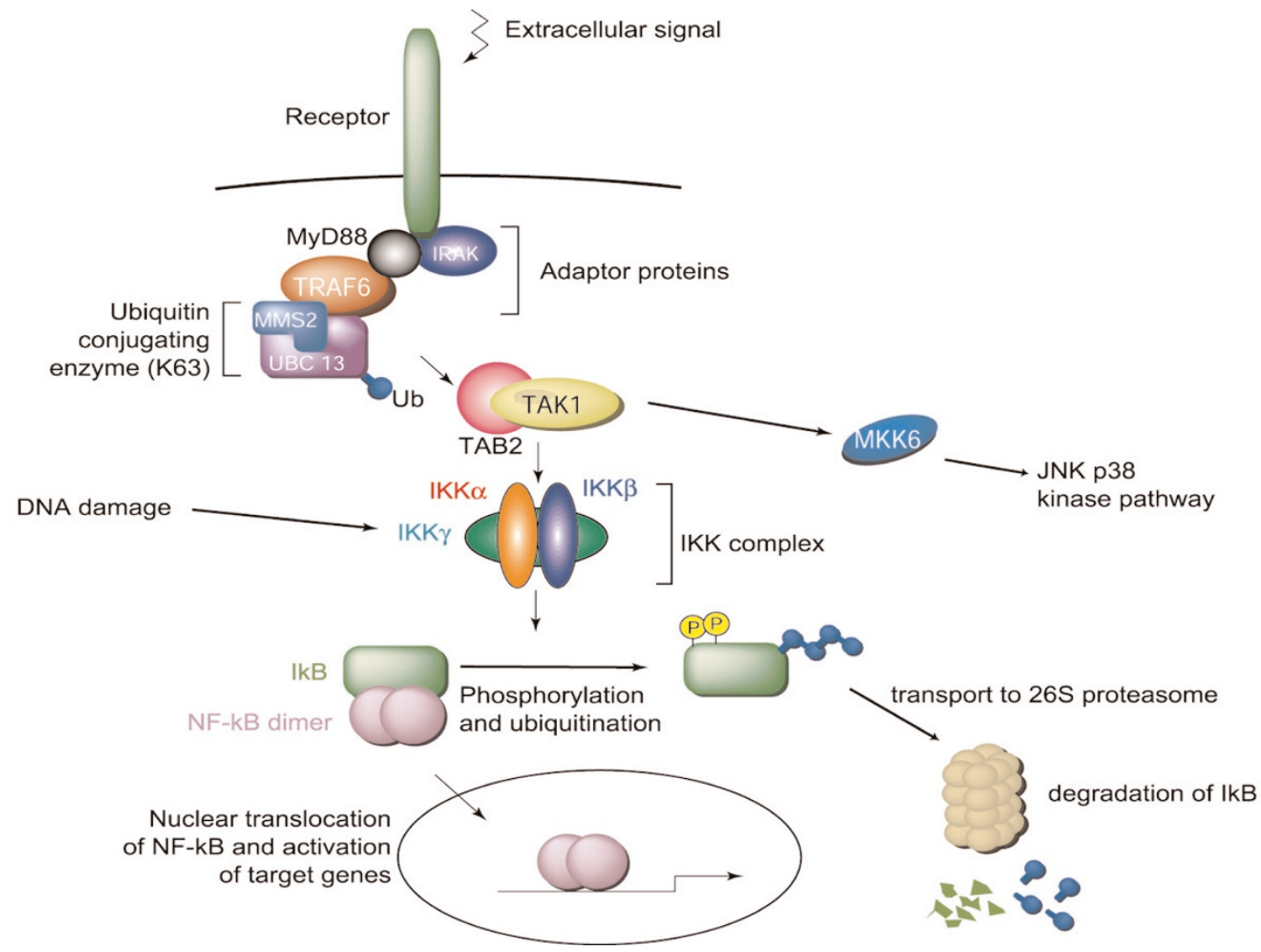

NF- $\mathrm{KB}$ signal transduction. Extracellular stimulation of microbial ligands such as lipolysaccharide trigger the canonical NF- $\mathrm{kB}$ pathway that leads to septic shock. Shortly after stimulation, a series of ubiquitination events occur that activate TAK 1 and IKK complexes. This ultimately promotes IKB $\alpha$ phosphorylation and its subsequent proteolysis, thereby allowing the translocation of NF-KB into the nucleus where it promotes the transcription of its target genes. IKK = IKB kinase; JNK =c-Jun N-terminal kinase; MKK6 = Mitogen-activated protein kinase kinase 6; MyD88= Myeloid differentiation primary response gene (88); NF = nuclear factor; TRAF $=$ TNF-receptor-associated factor.

Support for this assertion comes from in vivo experiments wherein the ubiquitin proteasome system was impaired in transgenic mice. Ubiquitin plays a role on several levels in NF-KB activation (Figure 2) [7,9]. Upon extracellular stimulation by LPS, adaptor proteins such as TNF-receptor-associated factor 6 (TRAF6; E3 ubiquitin ligase), IL-1 receptorassociated kinase 1 (IRAK-1) and MyD88 (Myeloid differentiation primary response gene (88)) are recruited to the cytoplasmic domain of the receptor [10]. Subsequently, TRAF6 interacts with UBC13/UEV1A, a heterodimer that catalyzes the synthesis of polyubiquitin chains assembled through linkage of the carboxyl terminus of one ubiquitin molecule to an internal lysine residue at position 63 of the subsequent ubiquitin molecule (K63-linked chains) [11-13]. K63-linked chains are the primary signal responsible for initiating a kinase cascade that recruits and activates TAK1-TAB2-TAB3 and the IKB kinase (IKK) complex (IKK $\alpha$, IKK $\beta$ and IKK $\gamma$ ) [14]. Specifically, TAK1-TAB2-TAB3 recognizes K63-linked chains, which may facilitate the oligermerization of the complex and promote autophosphorylation and activation of TAK1 [14]. TAK1 then phosphorylates the IKK complex, namely IKK $\beta$. IKK $\beta$ proceeds to phosphorylate $I \kappa B \alpha$, an inhibitor that sequesters $N F-\kappa B$ in the cytoplasm. Upon phosphorylation, I $\mathrm{KB} \alpha$ is ubiquitinated via a lysine 48 (K48) linkage and transported to the 26S proteasome for degradation (a process that can be disrupted by specific proteasome inhibitors $[15,16])$. NF- $\kappa B$ then translocates to the nucleus where it stimulates transcription of proinflammatory modulators that potentiate the symptoms of endotoxic shock.

Since K48- and K63-linked chains assemble early in the NF- $\kappa B$ pathway, one could speculate that transgenic animals expressing mutant isoforms of ubiquitin that interfere with chain assembly in a dominant negative manner (K63R or K48R mutant ubiquitin) would display disrupted NF- $\kappa$ B activation and, thereby, survive the induction of endotoxic shock induced by LPS. Remarkably, although all the K63R 
and wild-type animals showed symptoms of endotoxic shock necessitating humane euthanasia within 24 hours, more than half the K48R animals survived for 2 weeks, at which point the experiment was terminated (Figure 3 ). The more profound effects of K48R mutant ubiquitin in vivo suggests that K48R mutant ubiquitin interferes more strongly with NF- $\kappa B$ signaling. Therefore, the proteasome is likely a better target for anti-NF- $\kappa B$ intervention than the IKK cascade for treatment of septic shock. Clinically, our findings may help explain why Velcade has greater efficacy than the IKK inhibitor PS-1145 in blocking the activation of NF- $\mathrm{KB}$ in MM [17]. Moreover, it has become clearer that LPS triggers inflammatory cascades involving as many as 14 distinct signaling pathways, including the NF- $\mathrm{KB}$ pathway. Interestingly, many of the genes in these pathways are regulated by the proteasome [18]. Therefore, combined with our results, this may also help explain why targeting one aspect of a signaling cascade such as IKK might not be therapeutically beneficial. However, since the proteasome is a common regulator of LPS signaling and proteasome inhibitors such as Velcade are already being used in clinical trials for cancer, it is not difficult to imagine that drugs of this type could be administered in a bolus for the treatment of septic shock. In fact, a recent study by Reis and colleagues [19] also supports our notion of using proteasomal inhibition to provide protection against septic shock. However, further studies are required to determine the full potential of proteasomal inhibitors such as Velcade in the treatment of septic shock.

\section{Future: proteasome inhibition and animal experimentation}

There is much yet to be learned from in vivo systems of septic shock and proteasome inhibition. Ideally, one would like to survey the activity of NF- $\kappa B$ at the level of the whole organism in Velcade treated and untreated animals. Optimally, one would like to know how the NF-кB pathway functions in any tissue of interest (for example, the brain or lungs, where innate immunity is active). Preferably, this should be done in a living animal to facilitate monitoring of temporal changes. Conveniently, $3 \mathrm{X} N \mathrm{~N}-\mathrm{\kappa B}$ luciferase transgenic animals (in which transcription of luciferase is dependent on NF- $\kappa \mathrm{B}$ activation) have been developed, and such reagents could be used to validate the approach [20,21]. These animals could be injected with various doses of bacterial LPS to induce endotoxic shock followed by the administration of proteasome inhibitors such as Velcade. Subsequently, they would be injected with the substrate luciferin and imaged using an image intensifying CCD camera. If our prediction is correct, then there should be reduced signal in treated versus untreated animals and a better overall survival. Moreover, this model would also be amenable to testing the clinical significance of proteasome inhibition in acutely infected animals with progressive invasive infection by performing a cecal ligation and puncture (CLP) procedure, which leads to polymicrobial sepsis and septic shock. We believe that the $3 \mathrm{X} N \mathrm{~N}-\mathrm{\kappa B}$ luciferase CLP model would at least begin to
Figure 3

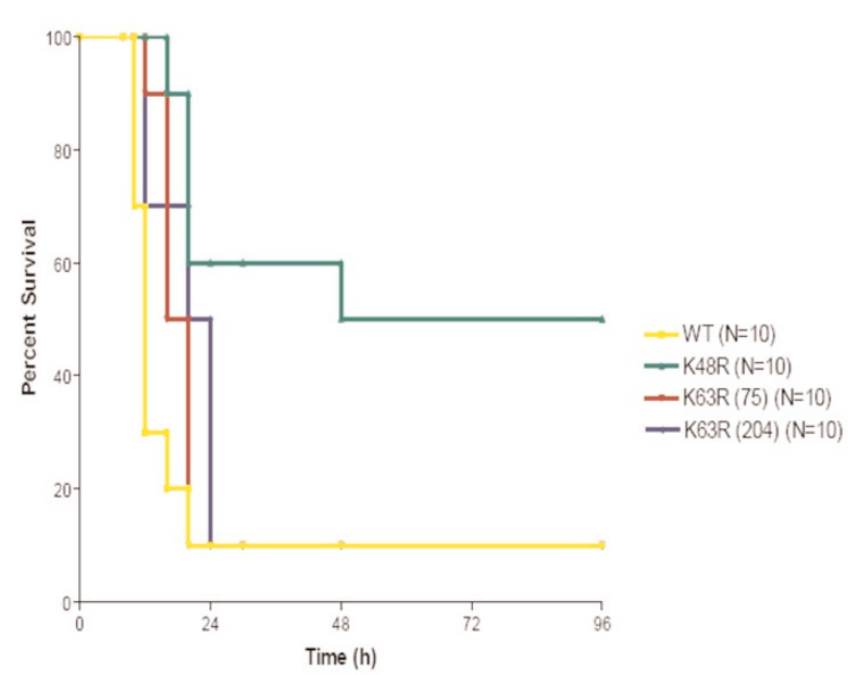

Mutant ubiquitin expressing mice are protected from endotoxic shock. Survival of FVB/N transgenic mice expressing wild-type (WT) and mutant ubiquitin (K48R or K63R) after a toxic intraperitoneal dose of $40 \mathrm{mg} / \mathrm{kg}$ of lipopolysaccharide. Two independent lines of K63R mice were evaluated (lines 75 and 204). The generation of these lines has been described in previous publications $[22,23]$.

address possible risks associated with proteasome inhibitors in preclinical models with an acute and invasive infection prior to testing such therapies in patients with similar acute and invasive infections. Interestingly, a recent study by Reis and colleagues [19] supports the notion of enhanced survival in a septic shock animal model with the use of proteasome inhibition combined with antibiotic treatment. This study at least is one of the first to demonstrate the safety of proteasome inhibition in acutely but invasively infected preclinical animal models. Although these results are encouraging, the animals were pretreated with proteasome inhibitors and antibiotics and, thus, experiments would need to be repeated in animals already undergoing septic shock. Overall, we believe that these results are at least encouraging with respect to safety and future use of proteasome inhibitors in septic shock patients with progressive infections.

We still expect much to be learned from the in vivo $3 \mathrm{X} N F-\kappa \mathrm{B}$ luciferase model using Velcade. Certainly, the $3 X \mathrm{NF}-\kappa \mathrm{B}$ luciferase mouse model alone or in combination with the CLP procedure will also be useful to test how conventional therapies compare to proteasome inhibitors, to optimize the pharmacological properties of such drugs for this application, and to determine if such agents should be used independently or in combination with current treatments.

\section{Conclusion}

Conventional therapies to treat endotoxic shock improve the survival of some, but not all, patients; thus, additional novel treatments are required to treat this condition. Proteasome 
inhibitors effectively target the main signaling pathway(s) active during septic shock, and genetic experiments suggest that inhibition of this system should be advantageous for clinical interventions. It would seem desirable, therefore, to evaluate the potential of existing or novel proteasome inhibitors to promote the survival of patients experiencing toxic shock.

\section{Competing interests}

The authors declare that they have no competing interests.

\section{Acknowledgements}

We thank Dr R Chiu (University of Maastricht) for contributing Figure 2 of this manuscript.

\section{References}

1. Cohen J: The immunopathogenesis of sepsis. Nature 2002, 420:885-891.

2. Mitsiades N, Mitsiades CS, Poulaki V, Chauhan D, Fanourakis G, Gu X, Bailey C, Joseph M, Libermann TA, Treon SP, Munshi NC, Richardson PG, Hideshima T, Anderson KC: Molecular sequelae of proteasome inhibition in human multiple myeloma cells. Proc Natl Acad Sci USA 2002, 99:14374-14379.

3. Jagannath S, Barlogie B, Berenson J, Siegel D, Irwin D, Richardson PG, Niesvizky R, Alexanian R, Limentani SA, Alsina M, Adams J, Kauffman M, Esseltine DL, Schenkein DP, Anderson KC: A phase 2 study of two doses of bortezomib in relapsed or refractory myeloma. Br J Haematol 2004, 127:165-172.

4. Orlowski RZ, Nagler A, Sonneveld P, Bladé J, Hajek R, Spencer A, San Miguel J, Robak T, Dmoszynska A, Horvath N, Spicka I, Sutherland HJ, Suvorov AN, Zhuang SH, Parekh T, Xiu L, Yuan Z, Rackoff W, Harousseau JL: Randomized phase III study of pegylated liposomal doxorubicin plus bortezomib compared with bortezomib alone in relapsed or refractory multiple myeloma: combination therapy improves time to progression. $J$ Clin Oncol 2007, 25:3892-3901.

5. Parrillo JE: Pathogenetic mechanisms of septic shock. N Engl J Med 1993, 328:1471-1477.

6. Danner RL, Elin RJ, Hosseini JM, Wesley RA, Reilly JM, Parillo JE: Endotoxemia in human septic shock. Chest 1991, 99:169-175.

7. Li Q, Verma IM: NF-kappaB regulation in the immune system. Nat Rev Immunol 2002, 2:725-734.

8. Wullaert A, Heyninck K, Janssens S, Beyaert R: Ubiquitin: tool and target for intracellular NF-kappaB inhibitors. Trends Immunol 2006, 27:533-540.

9. Chen ZJ: Ubiquitin signalling in the NF-kappaB pathway. Nature Cell Biol 2005, 7:758-765.

10. Courtois G, Israel A: NF-kappa B defects in humans: the NEMO/incontinentia pigmenti connection. Sci STKE 2000, 2000:PE1.11752619

11. Deng L, Wang C, Spencer E, Yang L, Braun A, You J, Slaughter C, Pickart C, Chen ZJ: Activation of the IkappaB kinase complex by TRAF6 requires a dimeric ubiquitin-conjugating enzyme complex and a unique polyubiquitin chain. Cell 2000, 103:351-361.

12. Lomaga MA, Yeh WC, Sarosi I, Duncan GS, Furlonger $C$, Ho A Morony S, Capparelli C, Van G, Kaufman S, van der Heiden A, Itie A, Wakeham A, Khoo W, Sasaki T, Cao Z, Penninger JM, Paige CJ, Lacey DL, Dunstan CR, Boyle WJ, Goeddel DV, Mak TW: TRAF6 deficiency results in osteopetrosis and defective interleukin-1, CD40, and LPS signaling. Genes Dev 1999, 13:10151024.

13. Wang C, Deng L, Hong M, Akkaraju GR, Inoue J, Chen ZJ: TAK1 is a ubiquitin-dependent kinase of MKK and IKK. Nature 2001, 412:346-351.

14. Kanayama A, Seth RB, Sun L, Ea CK, Hong M, Shaito A, Chiu YH, Deng L, Chen ZJ: TAB2 and TAB3 activate the NF-kappaB pathway through binding to polyubiquitin chains. Mol Cell 2004, 15:535-548.

15. Chen Z, Hagler J, Palombella VJ, Melandri F, Scherer D, Ballard D, Maniatis T: Signal-induced site-specific phosphorylation targets I kappa B alpha to the ubiquitin-proteasome pathway. Genes Dev 1995, 9:1586-1597.

16. Scherer DC, Brockman JA, Chen Z, Maniatis T, Ballard DW: Signal-induced degradation of I kappa B alpha requires sitespecific ubiquitination. Proc Natl Acad Sci USA 1995, 92: 11259-11263.

17. Hideshima T, Chauhan D, Richardson P, Mitsiades C, Mitsiades N, Hayashi T, Munshi N, Dang L, Castro A, Palombella V, Adams J, Anderson KC: NF-kappa B as a therapeutic target in multiple myeloma. J Biol Chem 2002, 277:16639-16647.

18. Shen J, Reis J, Morrison DC, Papasian C, Raghavakaimal S, Kolbert C, Qureshi AA, Vogel SN, Qureshi N: Key inflammatory signaling pathways are regulated by the proteasome. Shock 2006, 25:472-484.

19. Reis J, Tan X, Yang R, Rockwell CE, Papasian CJ, Vogel SN, Morrison DC, Qureshi AA, Qureshi N: A combination of proteasome inhibitors and antibiotics prevents lethality in a septic shock model. Innate Immun 2008, 14:319-329.

20. Alexander $\mathrm{G}$, Carlsen $\mathrm{H}$, Blomhoff R: Strong in vivo activation of NF-kappaB in mouse lenses by classic stressors. Invest Ophthalmol Vis Sci 2003, 44:2683-2688.

21. Carlsen H, Moskaug JO, Fromm SH, Blomhoff R: In vivo imaging of NF-kappa B activity. J Immunol 2002, 168:1441-1446.

22. Tsirigotis M, Tang MY, Beyers M, Zhang M, Woulfe J, Gray DA: Delayed spinocerebellar ataxia in transgenic mice expressing mutant ubiquitin. Neuropathol App/ Neurobio/ 2006, 32:26-39.

23. Tsirigotis $M$, Thurig S, Dube M, Vanderhyden BC, Zhang M, Gray $\mathrm{DA}$ : Analysis of ubiquitination in vivo using a transgenic mouse model. Biotechniques 2001, 31:120-126, 128, 130. 